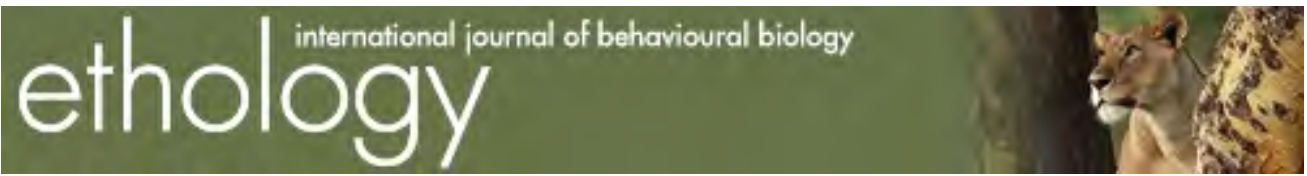

\title{
The male and female perspective in the link between male infant care and mating behaviour in Barbary macaques
}

\begin{tabular}{|c|c|}
\hline Journal: & Ethology \\
\hline Manuscript ID & ETH-18-0169.R2 \\
\hline Manuscript Type: & Research Paper \\
\hline $\begin{array}{r}\text { Date Submitted by the } \\
\text { Author: }\end{array}$ & $\mathrm{n} / \mathrm{a}$ \\
\hline Complete List of Authors: & $\begin{array}{l}\text { Kuběnová, Barbora; Faculty of Science, University of South Bohemia, } \\
\text { Department of Zoology; Georg August University Göttingen, Department } \\
\text { of Behavioral Ecology; German Primate Center \& Georg August } \\
\text { University Göttingen, Göttingen, Leibniz ScienceCampus Primate } \\
\text { Cognition; Kyoto University Primate Research Institute, Kyoto University } \\
\text { Primate Research Institute } \\
\text { Ostner, J ulia; Georg-August-University, Department of Behavioral } \\
\text { Ecology; German Primate Centre, Research Group Primate Social } \\
\text { Evolution; German Primate Center \& Georg August University Göttingen, } \\
\text { Leibniz ScienceCampus Primate Cognition } \\
\text { Schülke, Oliver; Georg-August-University, Department of Behavioral } \\
\text { Ecology; German Primate Centre, Department of Behavioral Ecology; } \\
\text { German Primate Center \& Georg August University Göttingen, Leibniz } \\
\text { ScienceCampus Primate Cognition } \\
\text { Majolo, Bonaventura; University of Lincoln, Psychology } \\
\text { Šmilauer, Petr; Faculty of Science, University of South Bohemia, } \\
\text { Department of Ecosystem Biology } \\
\text { Waterman, James; University of Lincoln, School of Psychology } \\
\text { Tkaczynski, Patrick; University of Roehampton, Department of Life } \\
\text { Science; Max Planck Institute For Evolutionary Anthropology Department } \\
\text { of Evolutionary Genetics, Department of Primatology } \\
\text { Konečná, Martina; Faculty of Science, University of South Bohemia, } \\
\text { Department of Zoology }\end{array}$ \\
\hline keywords: & $\begin{array}{l}\text { male infant care, infant handling, paternal investment, mating effort, } \\
\text { Macaca sylvanus }\end{array}$ \\
\hline
\end{tabular}


1 Title: The male and female perspective in the link between male infant care and

\section{2 mating behaviour in Barbary macaques}

\section{Short title: Infant care and mating in macaques}

4 Barbora Kuběnováa,b,c,e*, Julia Ostner ${ }^{\mathrm{b}, \mathrm{d}, \mathrm{e}}$, Oliver Schülke ${ }^{\mathrm{b}, \mathrm{d}, \mathrm{e}}$, Bonaventura Majolof ${ }^{\mathrm{f}}$, Petr

$5 \quad \check{S}$ milauerg ${ }^{\mathrm{g}}$, James Waterman ${ }^{\mathrm{f}}$, Patrick Tkaczynski ${ }^{\mathrm{h}, \mathrm{i}}$, Martina Konečnáa

6 a Department of Zoology, Faculty of Science, University of South Bohemia, České 7 Budějovice, Czech Republic

8 b Department of Behavioral Ecology, Johann-Friedrich-Blumenbach Institute for 9 Zoology and Anthropology, Georg August University Göttingen, Göttingen, Germany

10 c Kyoto University Primate Research Institute, Inuyama, Japan

11 d Research Group Primate Social Evolution, German Primate Centre, Göttingen, 12 Germany

13 e Leibniz ScienceCampus Primate Cognition, German Primate Center \& Georg August 14 University Göttingen, Göttingen, Germany

15 f School of Psychology, University of Lincoln, Lincoln, United Kingdom

16 g Department of Ecosystem Biology, Faculty of Science, University of South Bohemia,

17 České Budějovice, Czech Republic

h Department of Life Science, University of Roehampton, London, United Kingdom

19 i Department of Primatology, Max Planck Institute for Evolutionary Anthropology, 
* Corresponding author: Barbora Kuběnová, Kyoto University Primate Research Institute, Kanrin 41-2, Inuyama, Aichi, Japan 484-8506. E-mail: kubebar@seznam.cz, phone number: $+81(0) 568-63-0284$

\section{Acknowledgement}

This study was supported by grant 009/2014/P and 04-151/2016/P provided by the Grant Agency of the University of South Bohemia, Christian-Vogel Fond for Field Research of the Gesllschaft für Primatologie and Leibniz ScienceCampus Primate Cognition. Barbora Kuběnová was supported by the scholarship of the German Academic Exchange Service DAAD and fellowship of Japan Society for the Promotion of Science (JSPS). We are grateful to the Haut Commissariat aux Eaux et Forêts et à la Lutte Contre la Desertification of Morocco for research permission (research permits No. 253/2013 and 26/2014), Professor Mohamed Mouna (Institute Scientifique, Rabat, Morocco), and Professor Mohamed Qarro (Ecole Nationale Forestière d'Ingénieurs, Salé, Morocco) for their invaluable support and cooperation during the field work. We particularly appreciate the advice and support of Josephine Kalbitz, Adeelia Goffe, Andreas Berghänel, Christopher Young, Christina Haunhorst, Stanislav Lhota and Andrew MacIntosh. We are thankful to field assistants who contributed to the data collection. We also want to thank Dr. Tom Tregenza for his insightful comments on the manuscript. We declare that there is no conflict of interests regarding the publication of this article. All applicable international, national, and/or institutional guidelines for the care and use of animals were followed.

\section{ABSTRACT}


Infant care from adult males is unexpected in species with high paternity uncertainty. Still, males of several polygynandrous primates engage in frequent affiliative interactions with infants. Two non-exclusive hypotheses link male infant care to male mating strategies. The paternal investment hypothesis views infant care as a male strategy to maximise the survival of sired offspring, while the mating effort hypothesis predicts that females reward males who cared for their infant by preferably mating with them. The paternal investment hypothesis predicts a positive relationship between the distribution of matings and subsequent infant care, whereas the mating effort hypothesis between care and subsequent matings. Both hypotheses are usually tested from the female perspective, - based on the proportion of a female's or her infant's interactions with a specific male relative to her or her infant's interactions with all males; but not from the male perspective, based on the proportion of a male's interactions with a specific female relative to his interactions with all females.

We tested the relationships between care and mating from both perspectives in Barbary macaques. Mating predicted subsequent care and care predicted subsequent mating when viewed from the male but not the female perspective. Males mainly cared for infants of their main mating partners, but infants were not mainly cared for by their likely father. Males mated more with the mothers of their favourite infants, but females did not mate more with the main caretakers of their infants.

We suggest that females do not choose their mating partners based on previous infant care, increasing paternity confusion. Males might try to increase paternal investment by distributing the care according to their own instead of female mating history. Further, males pursue females for mating opportunities based on previous care. 


\section{Kuběnová 4}

66

67

68

69

70

71

72

73

74

75

76

Keywords: Male infant care - infant handling - paternal investment - mating effort Macaca sylvanus

\section{INTRODUCTION}

Mammalian males and females differ in their reproductive strategies. Females are limited in the number of offspring they can produce by the time and energetic costs of gestation and lactation (Geary, 2015). Males are limited by the number of mating opportunities they can secure and face paternity uncertainty (Trivers, 1972). These differences lead to conflict between females and males, in which the two sexes use different strategies to increase their own fitness, sometimes constraining the fitness of the opposite sex (Gavrilets, Arnqvist, \& Friberg, 2001; Parker, 1979). The typical example of such a sexual conflict is the interplay between male infanticide, proposed to be an adaptive male strategy (Hrdy, 1979; van Schaik, Pradhan, \& van Noordwijk, 2004), and paternity confusion, a female counter-strategy against infanticide. However, sexual conflict is expressed by various behavioural strategies, including the number of mating partners, mating frequency and its timing, maintenance of intersexual relationships and relative parental investment (Stumpf, Martinez-Mota, Milich, Righini, \& Shattuck, 2011).

Postnatal maternal investment in the form of lactation is ubiquitous in mammals and typically extends to other forms of care-giving (Clutton-Brock \& Parker, 1992; Trivers, 1972). The degree of male paternal investment varies strongly across taxa. In the majority of mammalian species mothers are the sole caretakers, but in some species (e.g. some carnivores, rodents and primates; Woodroffe \& Vincent, 1994) males actively take care of infants. Sexual selection theory links the variation in male investment with paternity certainty (Trivers 1972). Males may forfeit mating opportunities when 
taking care of infants and, when paternity is uncertain, risk misdirecting paternal investment to the offspring of other males (Clutton-Brock \& Parker, 1992; Andreas Paul, Preuschoft, \& van Schaik, 2000; Trivers, 1972). It is thus expected that the higher the paternity uncertainty, the less likely males are to invest into infants.

Although the risk of misdirected paternal investment is likely to be high in polygynandrous primates, males in some species do associate closely with infants (Huchard et al., 2012), groom and carry them (Deag, 1980; Estrada \& Sandoval, 1977), support them in conflicts (Buchan, Alberts, Silk, Altmann, \& others, 2003; Minge, Berghänel, Schülke, \& Ostner, 2016) and protect them from harassment and infanticide (Palombit, Seyfarth, \& Cheney, 1997; Paul, Preuschoft, \& van Schaik, 2000). Two hypotheses explain such behaviour as a part of an adaptive male reproductive strategy. The paternal investment hypothesis (Trivers, 1972) proposes that males are able to assess their chances of paternity and direct their infant care accordingly, even in polygynandrous species. It suggests that the probability of a male to care for an infant increases with his chances of having sired the infant. Supporting this hypothesis, in yellow (Papio cynocephalus; Altmann, 2001) and olive baboons (P. anubis; Smuts, 1985) males were more likely to take care of infants if they had consorted (see Manson, 1997 for the definition) or mated with an infant's mother in the preceding mating season than if they did not consort/mate with her (see also Smuts \& Gubernick, 1992). In chacma baboons (P. ursinus), male-infant associations were predicted by consortship activities and/or social bonds between males and females (Buchan et al., 2003; Moscovice et al., 2010), that predicted paternity (Buchan et al. 2003). In crested macaques (Macaca nigra), the likelihood of male-infant affiliation was significantly higher if the male was present in the group at the infant's conception (Kerhoas et al., 2016). In Assamese (M. assamensis; 


\section{Kuběnová 6}

113 Ostner, Vigilant, Bhagavatula, Franz, \& Schülke, 2013) and rhesus macaques (M. 114 mulatta; Langos, Kulik, Mundry, \& Widdig, 2013) the distribution of copulations predicted the distribution of subsequent male infant care, suggesting that males estimate their paternity chances when distributing infant care.

The mating effort hypothesis (Seyfarth, 1978) views male infant care as a reproductive strategy to trade investment into infants for future mating opportunities with the infant's mother, who monitors male care and distributes subsequent mating accordingly (Seyfarth 1978; Smuts 1985). It predicts a positive relationship between care and subsequent mating (Ménard et al., 2001; Seyfarth, 1978; Smuts, 1985). Evidence of this pattern is rather weak in baboons (Nguyen, Van Horn, Alberts, \& Altmann, 2009; Weingrill, 2000) however, some findings supported this hypothesis in macaques. In Tibetan macaques (M. thibetana), the amount of infant care that a male provided predicted the number of females who later consorted with that male (Zhao, 1996). In Barbary macaques (M. sylvanus), males were likely to become the primary sexual partners of those females whose offspring they had previously cared for the most (Ménard et al. 2001), supporting the mating effort hypothesis. However, an earlier study on the same species did not find this pattern (Paul, Kuester, \& Arnemann, 1996). Indirect evidence might also come from mountain gorillas (Gorilla beringei beringei), where those males that were most involved in infant care had the highest lifetime fitness, although they did not direct care specifically to their own offspring (Rosenbaum, Vigilant, Kuzawa, \& Stoinski, 2018).

Both the paternal investment and mating effort hypotheses predict a link between the distributions of infant care and mating. The paternal investment hypothesis predicts a 
136 positive relationship between the distribution of current mating and infant care during the

137 subsequent birth season, whereas the mating effort hypothesis predicts a positive relationship between current infant care and subsequent mating. Notably, both patterns have been tested so far from the female perspective, that is based on the proportion of a female's or her infant's interactions with a specific male, relative to her/her infant's interactions with all males. Little attention has been paid to the perspective of males, i.e. the proportion of a male's interactions with a specific female/her infant, relative to his interactions with all females/her infants.

Although this difference may seem negligible, the two perspectives in fact provide different information. First, when testing whether mating predicts subsequent care, the female perspective is suitable to test the prediction of the paternal investment hypothesis, i.e. that males take into account the distribution of female matings across all males when distributing their infant care, because the probability of paternity is likely based on how often females mated with different males. However, the female perspective implies that males are able to monitor all matings in a group (i.e. use knowledge of third party interactions) which may not be the case in a promiscuous species. If males can only access their own mating history, a more parsimonious prediction is that males distribute care based on their own proportional mating with a specific female. To test this prediction, the link between mating and subsequent care needs to be investigated from the male perspective. Second, when testing whether care predicts subsequent mating, the female perspective is in accord with the original definition of the mating effort hypothesis, which assumes that females control the distribution of mating and prioritizes mating with those males that care the most for her infant (Seyfarth, 1978). However, the male perspective 


\section{Kuběnová 8}

opportunities) on the basis of infant care, possibly indicating that the distribution of male infant care is influenced by a male's effort to establish a long-term relationship with a female. In summary, testing the relationship between mating and male care from both the female and male perspectives may help to understand male care in the context of male and female reproductive effort and tap into the question of the importance of individual (own) and social (the other's perspective) information for reproductive strategies.

Barbary macaque reproduction is characterized by high seasonality (with mating mostly concentrated into a three month period), a high degree of female ovarian cycle synchrony (Brauch et al., 2008; Küster \& Paul, 1984; Taub, 1980b; Young et al., 2013) and promiscuity (Small 1990), all of which is likely to increase paternity confusion. Copulations are brief, are rarely non-ejaculatory and males rarely achieve more than one copulation during consociation (Taub 1982). A consociation is often terminated by females who mate with multiple males at rapid succession (Small, 1990). Males rarely exhibit mate-guarding and male reproductive skew is low (Bissonnette et al., 2011), which is possibly due to the inability of males to monopolize females. Females show cyclic changes in sexual behavior and sexual swellings (Brauch et al., 2007; Young et al., 2013; but see Small, 1990), but they also display post-oestrous swelling which is thought to increase paternity uncertainty (Young et al., 2013). Indeed, males also mate with females when the probability of the conception is low, including during post-conception periods (Young et al., 2013). Finally, females produce copulation calls which may function to induce male-male competition and lead to more effective paternity confusion (Pfefferle, Brauch, Heistermann, Hodges, \& Fischer, 2008; Semple, 1998). 
Although these characteristics likely increase paternity confusion, Barbary macaque males frequently interact with infants (Whitten, 1987). Interactions between males and infants can either take the form of dyadic interactions between a single male and an infant during which a male carries, cradles, and/or grooms an infant, or take the form of triadic male-infant-male interactions, during which two males jointly manipulate an infant (Taub, 1980b). Both interaction types are unevenly distributed among males as well as infants (Deag, 1980; Kubenova et al., 2017; Ménard et al., 2001; Taub, 1984). Triadic male-infant-male interactions in macaques are proposed to primarily serve a social function among males (Deag \& Crook, 1971; Kalbitz, Schülke, \& Ostner, 2017; Paul et al., 1996), but explanations for dyadic male-infant interactions remain inconclusive (e.g. Paul et al., 1996; Taub, 1980b). Previous studies on Barbary macaques have shown that males are the primary caretakers of neither their genetic offspring (Ménard et al., 2001; Ménard, Scheffrahn, Vallet, Zidane, \& Reber, 1992; Paul, Kuester, \& Arenmann, 1992) nor their likely offspring based on previous mating success (Paul et al. 1996), speaking against the paternal investment hypothesis. Instead, one study has shown that males are likely to become the primary sexual partners of those females whose offspring they had previously cared for the most (Ménard et al., 2001), supporting the mating effort hypothesis. The conclusions are based on the link between the care and mating viewed from the female perspective. The male perspective has not been investigated.

We investigated both the female and the male perspectives of the relationships between mating and subsequent care and between care and subsequent mating in Barbary macaques. This resulted into four predictions (Table 1): 
1) We tested the paternal investment hypothesis from the female perspective to assess whether males monitor female matings and preferentially care for infants who are likely to be their offspring, based on the male's mating history with a specific female. To this end we examined the relationship between mating and subsequent care, predicting that the more a female mated with a specific male (relative to all her matings) the more care her infant will subsequently receive from this male (relative to all male care the infant receives).

2) We tested the paternal investment hypothesis from the male perspective to assess whether males monitor their own previous matings when distributing infant car. We examined the relationship between mating and subsequent care, predicting that the more a male mated with a specific female (relative to all his matings), the more he will subsequently care of her infant (relative to all his infant care).

3) We tested the mating effort hypothesis from the female perspective to assess whether females reward males who cared for their infant by preferably mating with them. We examined the relationship between care and subsequent mating, predicting that the more care an infant received from a specific male (relative to all male care the infant received), the more the infant's mother will mate with him (relative to all her matings).

4) We tested the mating effort hypothesis from the male perspective to assess whether males preferentially pursue mothers of their preferred infants for mating opportunities. We examined the relationship between care and subsequent mating, predicting that the more a male cared for a specific infant (relative to all infant care from him), the more he will subsequently mate with the infant's mother (relative to all his matings). 


\section{METHODS}

Data collection

We conducted this study in Ifrane National Park in the Middle Atlas Mountains of Morocco $\left(33-240^{\circ} \mathrm{N}, 005-120^{\circ} \mathrm{W}\right)$ under the research permission (No. 253/2013, 26/2014) of the Haut Commissariat aux Eaux et Forêts et à la Lutte Contre la Désertification of Morocco. The research complied with international, national and/or institutional guidelines for the ethical treatment of primates and with Directive 2010/63/EU. We adhered to the legal requirements of Morocco and ASAB/ABS

Guidelines for the care and use of animals. We followed one group (Green Group) of macaques, which was well habituated to the presence of human observers. Focal continuous observations (Altmann, 1974) of infants were conducted by BK over two field seasons, including two consecutive birth seasons (April - August 2013, April - June 2014). All individuals including infants were individually recognized based on their physical features (facial features, specific coloration patterns on head when changing the fur for infants).

In both seasons the group consisted of 6 adult males (> 5 years), 1 subadult ( 5 years) male, and 6 adult females (> 5 years). There were nineteen juveniles in 2013, and twenty in 2014. All adult females gave birth in both seasons, resulting in six infants each season ( 5 females, 1 male, born between April 5 and 30 in 2013 and 3 females, 3 males, born between April 10 and 27 in 2014). Infants were followed for 2-hour observation sessions, during which all social interactions between the focal infant and adult males were recorded. We pseudorandomized the order in which infants were observed to ensure 
that they were all observed equally often at different times of day. In both seasons, we started data collection once four infants were born. Data collection on the twelve infants yielded a total of 903 hours of observation, 582 hours in 2013 (between 83 and 109 hours per infant, median $=101$ ), and 321 hours in 2014 (between 44 and 61 hours per infant, median $=55)$.

We recorded all interactions between the focal infant and adult male(s), indicative of male care or affiliation including the start and termination of proximity (within 1.5 distance) as well as start and termination of active male care and "passive" body contact (see below). The start of proximity was recorded when a male approached the infant (to within a $1.5 \mathrm{~m}$ radial distance), when an infant approached a male, or was brought to a male by another individual. The end of proximity was recorded when the infant left the male (or vice versa), or when the infant was carried away by another individual. Active male care included carrying, cradling and grooming; passive body contact was recorded once an infant was in body contact with a male without apparent involvement of a male (e.g. infant resting, crawling in body contact with a male or crawling over his body). Triadic male-infant-male interactions were not included in any of those categories, as they may be motivated by factors unrelated to our main question, e.g. male relationship management (Deag, 1980; Paul et al., 1996).

Mating behaviour and dyadic dominance-submission interactions were recorded ad libitum (Altmann, 1974) on adult macaques by several researchers between April 2013 and September 2014. All matings were recorded between October 2013 and February 2014 (further referred to as the mating season).

Data analysis 

index (CSI; Silk, Altmann, \& Alberts, 2006). We used five categories of affiliative dyadic interactions (recorded during focal observations and controlled for dyadic focal observation time) between males and infants to calculate the CSI, which were all positively correlated (row-wise matrix correlation, average row-wise tau: 0.68-0.76). These behavioural categories were (1) frequency and (2) duration of active male care, (3) duration of passive body contact, (4) frequency of male approaches into infant's $1.5 \mathrm{~m}$ proximity and (5) duration of time spent within 1.5 m proximity (excluding duration of passive body contact and active male care). (CSIm), in order to express the distribution of care from the infant's (corresponding with the female's) perspective and male's perspective, respectively. this infant formed with all males $(\overline{\text { Beh. infant - all males }})$ divided by the number of behavioural categories, i.e. five, following the formula

This quantified how much care the infant received from a particular male relative to all other males. 
296

297

298

301

302

303

304

305

306

307

308

309

310

311

312

313

314

315

316

male formed with all infants ( $\overline{\text { Beh. male - all infants }}$ ) divided by the number of categories, following the formula

$$
\operatorname{CSIm}=\frac{\sum_{\mathrm{i}=1}^{5} \text { Beh. infant }- \text { male } / \overline{\text { Beh. male }- \text { all infants }}}{5} .
$$

This quantified how much a particular male cared for a particular infant relative to all other infants. We assessed CSIs for both perspectives separately for birth season 2013 and 2014.

To assess mating distribution from the female perspective (female matings), we calculated the proportion of matings each male achieved with a female from all matings of this female (with all males). To assess mating distribution from the male perspective (male matings), we calculated the proportion of a male's matings with each female from all his matings (with all females). Values could range between 0 and $1(0=$ no matings with given partner, 1 = all matings with given partner only). We run row-wise matrix correlation (using Matman 1.1.4 program; Netto, Hanegraaf, \& De Vries, 1993) to compare female and male matings.

To assess dominance rank, we entered dominance-submission interactions (recorded as Ad libitum) into a winner-loser matrix and built a hierarchy based on the standardized normalized David's score (De Vries, Stevens, \& Vervaecke, 2006). The hierarchy was assessed separately for males and females, and birth season 2013 and birth season 2014. Dominance rank was based on 213 interactions in females and 45 in males in 2013, and 249 in females and 71 in males in 2014, respectively.

\section{Statistical analysis}


We used linear mixed models (LMMs) using the lme4 package (Bates, Maechler,

Bolker, Walker, \& others, 2014) in R 3.1.1 (R Core Team, 2014). To evaluate the effects

of the predictors we computed the $95 \%$ confidence intervals (using the confint function

in lme4). We constructed a separate model for each of four predictions. In all four models,

female/infant and male IDs were entered as random effects. Every possible male-female,

respectively male-infant combination $(\mathrm{N}=36)$ entered the analysis as an independent data

point. Depending on the perspective (female versus male), we controlled for the male,

respectively female dominance rank.

\section{RESULTS}

All infants were observed in $1.5 \mathrm{~m}$ proximity with all males and in active care or passive body contact with 0-6 males (median=6) over the respective birth seasons. Infants spent between $0 \%$ and $15 \%$ of observation time in active care (mean=3.6 \pm SD 5.3\%) and between $0 \%$ and $4 \%$ in passive body contact (mean=5.2 \pm SD $6.1 \%$ ). Only one infant was never observed in active care or passive body contact with any male. From 36 possible male-infant dyads, $18(50 \%)$ dyads were observed in active care and/or passive body contact in 2013 and $25(69 \%)$ dyads in 2014. CSIs were calculated based on 5,829 interactions in period 2013 (range per infant $=221-2,206$; mean=972 \pm SD 937) and 4,529 interactions in 2014 (range per infant $=404-1,525$, mean $=755 \pm$ SD 421). CSI values ranged between 0.027 and 4.150 for the infant perspective (median=0.471) and between 0.007 and 4.602 for the male perspective (median=0.379). least five mating partners from a possible six. The proportion of female matings with 
different males ranged between 0 and 0.50 (median=0.14). The proportion of male matings with different females ranged between 0 and 0.58 (median=0.10). Proportions of female and male matings significantly correlated $(\mathrm{Kr}$ test, row-wise tau=0.461, $\mathrm{p}<001)$. Further details about the distributions of CSIs and matings are provided as supporting information in the electronic supplement.

\section{Model 1: Paternal investment hypothesis, female perspective}

The care an infant received from a male, relative to all male care that infant received from any male was neither predicted by how often, in the previous mating season, the infant's mother had mated with this male relative to all her matings, (LMM: Estimate $=-0.623 ; \mathrm{SE}=1.778 ; \mathrm{t}=-0.351 ; \mathrm{CI} 95 \%=-4.050,2.803)$ nor by male dominance $\operatorname{rank}(\mathrm{GLMM}:$ Estimate $=0.021 ; \mathrm{SE}=0.043 ; \mathrm{t}=0.484 ; \mathrm{CI} 95 \%=-0.063,2.803)$.

\section{Model 2: Paternal investment hypothesis, male perspective}

The care a male directed to a specific infant, relative to all the care provided by that male, was predicted by how often, in the previous mating season, that male had mated with the infant's mother relative to all his matings (LMM: Estimate $=3.949 ; \mathrm{SE}=1.401$; CI95\% $=1.248,6.651)$ and was not affected by female dominance rank (GLMM: Estimate $=0.019 ; \mathrm{SE}=0.026 ; \mathrm{CI} 95 \%=-0.031,0.069)$.

\section{Figure 1 placed here}

\section{Model 3: Mating effort hypothesis, female perspective}

How often a female mated with a specific male relative to all her matings, was neither predicted by the amount of care her infant had received from the male relative to all care the infant had received, in the previous birth season (LMM: Estimate $=0.014$; SE 
$362=0.016 ;$ CI95\% $=-0.092 ; 0.045)$, nor by male rank $(\mathrm{LMM}$ : Estimate $=0.011 ; \mathrm{SE}=0.006$;

Model 4: Mating effort hypothesis, male perspective his infant care), in the previous birth season (LMM: Estimate $=0.039 ; \mathrm{SE}=0.018 ; \mathrm{CI} 95 \%$ $=0.003 ; 0.074)$, but was not predicted by female rank (LMM: Estimate $=0.003 ; \mathrm{SE}=$ 0.0004; CI95\% = -004; 0.010).

\section{DISCUSSION}

We investigated in wild Barbary macaques the relationship between mating and subsequent care, and between care and subsequent mating both from the female and the male perspective to test two non-exclusive hypotheses, the paternal investment and the mating effort hypothesis. When tested from the female perspective, neither hypotheses were supported; conversely both the paternal investment and the mating effort hypotheses were supported when tested from the male perspective.

Model 1: Paternal investment hypothesis, female perspective own offspring. Based on genetic data there is evidence for this pattern in some (e.g.,

381 yellow baboons: Buchan et al., 2003; Onyango, Gesquiere, Altmann, \& Alberts, 2013; 382 chacma baboons: Huchard et al., 2012; rhesus macaques: Langos et al., 2013; Assamese 
macaques: Ostner et al., 2013), but not in other species (Kerhoas et al., 2016; Paul et al., 1996). A number of behavioural studies (rhesus macaques: Berenstain, Rodman, \& Smith, 1981; Assamese macaques: Ostner et al., 2013; chacma baboons: Moscovice et al., 2010) suggest that males may distribute care depending on their previous mating history, potentially estimating their paternity chances (per infant) and adjusting care levels accordingly. This adjustment based on past mating history was neither confirmed in previous studies on Barbary macaques, where the mother's main sexual partner did not become the infant's main caretaker (Ménard et al., 2001; Paul et al., 1996), nor in the present study.

While this result does not align with the paternal investment hypothesis, we cannot conclusively reject it. Mating frequency may not be positively related to an increased probability of siring an infant (Ménard et al. 2001). Given that genetic data on paternity were not available in our study, we cannot rule out that genetic fathers did indeed become the main caretakers of their offspring despite having mated less than other males with the infant's mother. In this case, males may base their approximation of siring success on information we did not record, for example the timing of mating in relation to conception probability (Brauch et al., 2007; Semple \& McComb, 2000; Young, Majolo, Heistermann, Schülke, \& Ostner, 2013). It is unclear whether Barbary macaque males are able to estimate the timing of conception based on female cues. Although the size of sexual swellings may serve as a reliable signal of female fertility (Brauch et al., 2007; Young et al., 2013; but seeSmall, 1990), males also mate with females when the probability of the conception is low, and even during post-conception periods (Young et al., 2013). Further, females in our study mated in rapid succession with up to four different 
406 males within one day. Thus, even if males could have estimated and considered the

407 reproductive state of their mating partners, paternity uncertainty likely remained high.

408

409

410

411

412

413

414

415

416

417

418

419

420

421

422

423

424

425

Model 2: Paternal investment hypothesis, male perspective

Female promiscuity may make it difficult for males to keep track of female matings with other males. This might be why our and other studies (Ménard et al. 2001; Paul et al. 1996) do not support the paternal investment hypothesis when tested from the female perspective. Instead, we found that males cared more for the infants of their most frequent mating partners, supporting the paternal investment hypothesis from the male perspective. It is possible, that under the conditions of female promiscuity and incomplete fertility information, a male's best strategy to increase paternal investment might be to track their own matings and base care pattern on their own mating history. The crucial difference here is between private versus third party knowledge; only if the information males have on female mating activity with any male is sufficiently reliable, males can match their subsequent infant care accordingly. If such a third party information is noisy, males may use their own matings across females as a proxy. In our study, the proportions of female and male matings were correlated, thus tracking of one's own mating history (in the absence of more reliable information about paternity), may result in an adaptive benefit in terms of a decreased probability of directing care to a non-related infant. However, this benefit may remain obscure in the results due to our small sample size and lack of paternity data, which is a limitation of our study. However, if males make mistakes when estimating their paternity, we cannot exclude that even with genetic data, the relationship between care and paternity might be ambiguous in studies with small sample sizes. 

macaques, is improved access to infants for frequent triadic male-infant-male interactions. These interactions help males to establish and maintain social bonds with other males (Kalbitz et al. 2017; Kuběnová et al., 2019; Kümmerli \& Martin, 2008; Paul et al., 1996) which may reduce aggression among males (Deag \& Crook, 1971) and help them to retain support in coalition (Paul et al., 1996). The benefit of social bonding may outweigh the cost of infant care. Concentrated in birth season, infant care in Barbary macaques does not represent a significant cost in terms of lost mating opportunities. The high body weight ratio between males and infants (Fooden, 2007) also suggests relatively low cost in terms of energy investment (Woodroffe \& Vincent, 1994; Wright, 1990).

\section{Mating effort hypothesis, female perspective}

In contrast to the paternal investment hypothesis, the mating effort hypothesis proposes that males benefit from infant care if it increases their subsequent mating success with the infants' mothers (Seyfarth, 1978; Smuts, 1985; Smuts \& Gubernick, 1992). That is, if a male provides an infant with care the mother may subsequently provide that male with mating privileges (Hector, Seyfarth, \& Raleigh, 1989; Small, 1989). Consequently, the relationship between care and subsequent mating should be most apparent in species with a high potential for female mate choice (Seyfarth, 1978; Smuts, 1985). Female Barbary macaques are very active in sexual interactions (Small, 1990), initiating and terminating consortship (Taub, 1980a, p.292), and using copulations calls to manipulate paternity (Pfefferle et al., 2008; Semple, 1998). In line with this active sexual role of 450 females, the mating effort hypothesis from the female perspective was supported in a previous study on Barbary macaques, showing that females preferentially mated with 
453

454

455

456

457

458

459

460

461

462

463

464

465

466

467

468

469

470

471

472

473

474

475

as well as results of yet another study on Barbary macaques (Paul et al., 1996), did not provide evidence for the mating effort hypothesis as females did not adjust their mating rate depending on the amount of care their infants had received from specific males prior to the mating season. It is possible that the female active role in sexual behaviour does not reflect mate choice but aids females to mate with as many males as possible to increase paternity confusion (Small, 1990; Taub, 1980a). The importance of paternity confusion has been linked to the degree of the risk of infanticide by males (Hrdy, 1979; van Noordwijk \& van Schaik 2000). In Barbary macaques, females might benefit from paternity confusion by reducing the risk of infanticide (Hrdy, 1979; van Noordwijk \& van Schaik 2000) and also by securing male care for their offspring from several males (Taub, 1980a but see also Small, 1990).

\section{Model 4: Mating effort hypothesis, male perspective}

From the male perspective, the relationship between infant care and subsequent mating holds; males were more likely to mate with those females whose infants they cared for more in the previous birth season. This does not support the original formulation of the mating effort hypothesis, which proposes increased male mating success based on previous infant care from the female perspective. Instead, it is consistent with the "friends with benefits hypothesis" (Ostner et al., 2013), which relates mating patterns to stable affiliative relationships between the sexes. The influence of male-female affiliative relationships on the distribution of male care for infants has been demonstrated in chimpanzees (Langergraber, Mitani, Watts, \& Vigilant, 2013), and several species of baboons (Goffe, Zinner, \& Fischer, 2016; Moscovice et al., 2010; Palombit et al., 1997; Städele et al., 2019; Weingrill, 2000) and macaques (Aureli \& Yates, 2010; Haunhorst, 
476 Schülke, \& Ostner, 2016; Hill, 1990; Kerhoas et al., 2016; Kulik, Amici, Langos, \&

477 Widdig, 2015; Massen et al., 2012; Ostner et al., 2013), but not yet in Barbary macaques

478 (Small, 1990). It is possible that males establish affiliative relationships with females with

479 whom they also preferentially mate. Females tolerate those males, allowing them to mate

480 with them and to interact with their infants. Still, it would be males who primarily choose

481 their mating partners. The pattern is male driven, thus cannot be explained by the "extended mating effort hypothesis" (which assumes that the pattern is a product of female choice for mating partners: Smuts \& Gubernick, 1992). In accordance with the "extended mating effort hypothesis", however, we conclude that the relationship between mating and subsequent care does not necessarily indicate paternal investment. Malefemale relationships may mediate both, the relationship between infant care and subsequent mating as well as between mating and subsequent care, making it difficult to distinguish between the mating effort and paternal investment hypotheses. These stable relationships may also help males to reduce paternity confusion and increase personal mating success with the female friends at the same time. i.e. males taking care of consecutive offspring of the same females. Specifically, in Barbary macaques this stability may be beneficial in relation to the high frequency of male-infant-male interactions, during which two males manipulate one infant together and which help males to manage relationships with other males (Kalbitz et al., 2017; Kuběnová et al., 2019; Paul et al., 1996, Taub et al. 1980). The stable pattern may reduce 497 competition over infants used in these interactions (Kalbitz et al., 2017; Paul et al., 1996), 498 and make those interactions more effective tools for male relationship management 499 (Kubenova et al., 2017; Ogawa, 1995; Paul et al., 1996). 
500

501

502

503

504

505

506

507

508

509

510

511

512

513

514

515

516

517

518

519

520

521

522

\section{Conclusion}

Sexual selection theory predicts that males and females employ different strategies to increase their fitness, and that some of these strategies may constrain the fitness of the opposite sex (Gavrilets et al., 2001; Parker, 1979). Among others, females and males may adjust the distribution of mating and the extent of infant care. By investigating the link between male infant care and mating in Barbary macaques, we did not confirm the prediction of the mating effort hypothesis from the female perspective. Instead, females seem to increase paternity uncertainty by mating with many males, regardless of care their infant received from particular males. The promiscuous mating behaviour of females makes it difficult for males to track other's mating behaviour rendering such third party knowledge unreliable. This may explain why males turn to direct information on how they distributed their mating across females when making decisions about how to allocate infant care. Males mated more with mothers of infants they had cared for most in the previous season. An untested possibility is that males establish long-term relationships with mothers of their preferred infants who they also pursue for mating opportunities.

Thus, the distribution of care and mating in Barbary macaques may be the outcome of contrasting male and female interests in sexual conflict (such as a male's effort for paternal investment constrained by the female's interest to confuse paternity), cognitive constraints (such as the limited ability to track all matings of a female) and additional not immediately reproductive interests (such as the use of infants for maleinfant-male interactions). Future research will benefit from more detailed information of female sexual behaviour indicative of female choice, physiological information on conception probability, and genetic paternity data. Future studies may also pay close 
523

524

525

526

527

528

529

530

531

532

533

534

535

536

537

538

539

540

541

542

543

544

545

attention to intersexual relationships and the role of infants in choosing male care partners.

\section{BIBLIOGRAPHY}

Altmann, J. (1974). Observational study of behavior: sampling methods. Behaviour, 49, 227-266. doi:10.1163/156853974X00534

Altmann, J. (2001). Baboon mothers and infants. Cambridge, MA: Harvard University Press

Aureli, F., \& Yates, K. (2010). Distress prevention by grooming others in crested black macaques. Biology Letters, 6, 27-29. doi:10.1098/rsbl.2009.0513

Bates, D., Maechler, M., Bolker, B., Walker, S., \& others. (2014). lme4: Linear mixedeffects models using Eigen and S4. R Package Version, 1, 1-23. doi:10.1111/j.1600-0706.2009.17726.x

Berenstain, L., Rodman, P. S., \& Smith, D. G. (1981). Social relations between fathers and offspring in a captive group of rhesus monkeys (Macaca mulatta). Animal Behaviour, 29, 1057-1063. doi:10.1016/S0003-3472(81)80058-9

Bissonnette, A., Bischofberger, N., \& van Schaik, C. P. (2011). Mating skew in Barbary macaque males: the role of female mating synchrony, female behavior, and malemale coalitions. Behavioral Ecology and Sociobiology, 65, 167-182. doi:10.1007/s00265-010-1023-z

Brauch, K., Hodges, K., Engelhardt, A., Fuhrmann, K., Shaw, E., \& Heistermann, M. (2008). Sex-specific reproductive behaviours and paternity in free-ranging Barbary macaques (Macaca sylvanus). Behavioral Ecology and Sociobiology, 62, 1453-1466. doi:10.1007/s00265-008-0575-7 
546 Brauch, K., Pfefferle, D., Hodges, K., Möhle, U., Fischer, J., \& Heistermann, M.

547

548

549

550

551

552

553

554

555

556

557

558

559

560

561

562

563

564

565

566

567

568

(2007). Female sexual behavior and sexual swelling size as potential cues for males to discern the female fertile phase in free-ranging Barbary macaques (Macaca sylvanus) of Gibraltar. Hormones and Behavior, 52, 375-383. doi:10.1016/j.yhbeh.2007.06.001

Buchan, J. C., Alberts, S. C., Silk, J. B., Altmann, J., \& others. (2003). True paternal care in a multi-male primate society. Nature, 425, 179-181. doi:10.1038/nature01866

Clutton-Brock, T. H., \& Parker, G. A. (1992). Potential reproductive rates and the operation of sexual selection. Quarterly Review of Biology, 67, 437-456. doi:10.1086/417793

De Vries, H., Stevens, J. M., \& Vervaecke, H. (2006). Measuring and testing the steepness of dominance hierarchies. Animal Behaviour, 71, 585-592. doi:10.1016/j.anbehav.2005.05.015

Deag, J. M. (1980). Interactions between males and unweaned Barbary macaques: testing the agonistic buffering hypothesis. Behaviour, 75, 54-80. doi:10.1163/156853980X00564

Deag, J. M., \& Crook, J. H. (1971). Social behavior and 'agonistic buffering'in the wild Barbary macaque Macaca sylvana L. Folia Primatologica, 15, 183-200. doi:10.1159/000155378

Estrada, A., \& Sandoval, J. M. (1977). Social relations in a free-ranging troop of stumptail macaques (Macaca arctoides): male-care behaviour I. Primates, 18, 793-813. doi:10.1007/BF02382931 
569 Fooden, J. (2007). Systematic review of the Barbary macaque, Macaca sylvanus

570

571

572

573

574

575

576

577

578

579

580

581

582

583

584

585

586

587

588

589

590

591

592

(Linnaeus, 1758). Fieldiana Zoology, 113, 1-60. doi:10.3158/00150754(2007)113[1:SROTBM]2.0.CO;2

Gavrilets, S., Arnqvist, G., \& Friberg, U. (2001). The evolution of female mate choice by sexual conflict. Proceedings of the Royal Society of London. Series B:

Biological Sciences, 268, 531-539. doi:10.1098/rspb.2000.1382

Geary, D. C. (2015). Evolution of paternal investment. The Handbook of Evolutionary Psychology, 1-18. doi:10.1002/9781119125563.evpsych120

Goffe, A. S., Zinner, D., \& Fischer, J. (2016). Sex and friendship in a multilevel society: behavioural patterns and associations between female and male Guinea baboons. Behavioral Ecology and Sociobiology, 70, 323-336. doi:10.1007/s00265-0152050-6

Haunhorst, C. B., Schülke, O., \& Ostner, J. (2016). Opposite-sex social bonding in wild Assamese macaques. American Journal of Primatology, 78, 872-882. doi:10.1002/ajp. 22554

Hector, A. C. K., Seyfarth, R. M., \& Raleigh, M. J. (1989). Male parental care, female choice and the effect of an audience in vervet monkeys. Animal Behaviour, 38, 262-271. doi:10.1016/S0003-3472(89)80088-0

Hill, D. A. (1990). Social relationships between adult male and female rhesus macaques: II. Non-sexual affiliative behaviour. Primates, 31, 33-50. doi:10.1007/BF02380860

Hrdy, S. B. (1979). Infanticide among animals: a review, classification, and examination of the implications for the reproductive strategies of females. Ethology and Sociobiology, 1, 13-40. doi:10.1016/0162-3095(79)90004-9 
593

594

595

596

597

598

599

600

601

602

603

604

605

606

607

608

609

610

611

612

613

614

615

616

Huchard, E., Charpentier, M. J., Marshall, H., King, A. J., Knapp, L. A., \& Cowlishaw, G. (2012). Paternal effects on access to resources in a promiscuous primate society. Behavioral Ecology, 24, 229-236. doi:10.1093/beheco/ars158

Kalbitz, J., Schülke, O., \& Ostner, J. (2017). Triadic male-infant-male interaction serves in bond maintenance in male Assamese macaques. PloS One, 12, e0183981. doi:10.1371/journal.pone.0183981

Kerhoas, D., Kulik, L., Perwitasari-Farajallah, D., Agil, M., Engelhardt, A., \& Widdig, A. (2016). Mother-male bond, but not paternity, influences male-infant affiliation in wild crested macaques. Behavioral Ecology and Sociobiology, 70, 1117-1130. doi:10.1007/s00265-016-2116-0

Kerhoas, D., Kulik, L., Perwitasari-Farajallah, D., Agil, M., Engelhardt, A., \& Widdig, A. (2016). Mother-male bond, but not paternity, influences male-infant affiliation in wild crested macaques. Behavioral Ecology and Sociobiology, 70, 1117-1130. doi:10.1007/s00265-016-2116-0

Kubenova, B., Konecna, M., Majolo, B., Smilauer, P., Ostner, J., \& Schülke, O. (2017). Triadic awareness predicts partner choice in male-infant-male interactions in Barbary macaques. Animal Cognition, 20, 221-232. doi:10.1007/s10071-016$1041-y$

Kuběnová, B., Ostner, J., Schülke, O., Majolo, B., Šmilauer, P., \& Konečná, M. (2019). The effect of dominance rank on the distribution of different types of male-nfant-male interactions in Barbary macaques (Macaca sylvanus). International Journal of Primatology, 1-16. doi:10.1007/s10764-019-00086-X

Kulik, L., Amici, F., Langos, D., \& Widdig, A. (2015). Sex differences in the development of social relationships in rhesus macaques (Macaca mulatta). 
International Journal of Primatology, 36, 353-376. doi:10.1007/s10764-0159826-4

Kümmerli, R., \& Martin, R. D. (2005). Male and female reproductive success in Macaca sylvanus in Gibraltar: no evidence for rank dependence. International Journal of Primatology, 26, 1229-1249. doi:10.1007/s10764-005-8851-0

Kümmerli, R., \& Martin, R. D. (2008). Patterns of infant handling and relatedness in Barbary macaques (Macaca sylvanus) on Gibraltar. Primates, 49, 271-282.

Küster, J., \& Paul, A. (1984). Female reproductive characteristics in semifree-ranging Barbary macaques (Macaca sylvanus L. 1758). Folia Primatologica, 43, 69-83. $10.1159 / 000156173$

Langergraber, K. E., Mitani, J. C., Watts, D. P., \& Vigilant, L. (2013). Male-female socio-spatial relationships and reproduction in wild chimpanzees. Behavioral Ecology and Sociobiology, 67, 861-873. doi:10.1007/s00265-013-1509-6

Langos, D., Kulik, L., Mundry, R., \& Widdig, A. (2013). The impact of paternity on male-infant association in a primate with low paternity certainty. Molecular Ecology, 22, 3638-3651. doi:10.1111/mec.12328

Manson, J. H. (1997). Primate consortships: a critical review. Current Anthropology, 38, 353-374. doi:10.1007/BF02381951

Massen, J. J., Overduin-de Vries, A. M., de Vos-Rouweler, A. J., Spruijt, B. M., Doxiadis, G. G., \& Sterck, E. H. (2012). Male mating tactics in captive rhesus macaques (Macaca mulatta): the influence of dominance, markets, and relationship quality. International Journal of Primatology, 33, 73-92. doi:10.1007/s10764-011-9552-5 
640 641

642

643

644

645

646

647

648

649

650

651

652

653

654

655

656

657

658

659

660

661

662

Ménard, N., Scheffrahn, W., Vallet, D., Zidane, C., \& Reber, C. (1992). Application of blood protein electrophoresis and DNA fingerprinting to the analysis of paternity and social characteristics of wild Barbary macaques. In R. D. Martin, A. F. Dixson, \& E. J. Wickings (Eds.), Paternity in primates: genetic tests and theories (pp 155-174). Karger Publishers. doi:10.1159/000421080

Ménard, N., von Segesser, F., Scheffrahn, W., Pastorini, J., Vallet, D., Gaci, B., ... Gautier-Hion, A. (2001). Is male-infant caretaking related to paternity and/or mating activities in wild Barbary macaques (Macaca sylvanus)? Comptes Rendus de l'Académie des Sciences. Série III, Sciences de la Vie, 324, 601. doi:10.1016/S0764-4469(01)01339-7

Minge, C., Berghänel, A., Schülke, O., \& Ostner, J. (2016). Patterns and consequences of male-infant relationships in wild Assamese macaques (Macaca assamensis). International Journal of Primatology, 37, 350-370. doi:10.1007/s10764-0169904-2

Moscovice, L. R., Di Fiore, A., Crockford, C., Kitchen, D. M., Wittig, R., Seyfarth, R. M., \& Cheney, D. L. (2010). Hedging their bets? Male and female chacma baboons form friendships based on likelihood of paternity. Animal Behaviour, 79, 1007-1015. doi:10.1016/j.anbehav.2010.01.013

Netto, W. J., Hanegraaf, P. L., \& De Vries, H. (1993). Matman: a program for the analysis of sociometric matrices and behavioural transition matrices. Behaviour, 125, 157-175. doi:10.1163/156853993X00218

Nguyen, N., Van Horn, R. C., Alberts, S. C., \& Altmann, J. (2009). "Friendships" between new mothers and adult males: adaptive benefits and determinants in wild 
663

664

665

666

667

668

669

670

671

672

673

674

675

676

677

678

679

680

681

682

683

684

685

baboons (Papio cynocephalus). Behavioral Ecology and Sociobiology, 63, 13311344. doi:10.1007/s00265-009-0786-6

Ogawa, H. (1995). Bridging behavior and other affiliative interactions among male Tibetan macaques (Macaca thibetana). International Journal of Primatology, 16, 707-729. doi:10.1007/BF02735716

Onyango, P. O., Gesquiere, L. R., Altmann, J., \& Alberts, S. C. (2013). Testosterone positively associated with both male mating effort and paternal behavior in savanna baboons (Papio cynocephalus). Hormones and Behavior, 63, 430-436. doi:10.1016/j.yhbeh.2012.11.014

Ostner, J., Vigilant, L., Bhagavatula, J., Franz, M., \& Schülke, O. (2013). Stable heterosexual associations in a promiscuous primate. Animal Behaviour, 86, 623631. doi:10.1016/j.anbehav.2013.07.004

Palombit, R. A., Seyfarth, R. M., \& Cheney, D. L. (1997). The adaptive value of 'friendships' to female baboons: experimental and observational evidence. Animal Behaviour, 54, 599-614. doi:10.1006/anbe.1996.0457

Parker, G. A. (1979). Sexual selection and sexual conflict. In M. B. Blum \& N. A. Blum (Eds.), Sexual selection and reproductive competition in insects (pp. 123-66). New York: Academic Press.

Paul, A. (1999). The socioecology of infant handling in primates: Is the current model convincing? Primates, 40, 33-46. doi:10.1007/BF02557700

Paul, A., Kuester, J., \& Arenmann, J. (1992). DNA fingerprinting reveals that infant care by male Barbary macaques (Macaca sylvanus) is not paternal investment. Folia Primatologica. doi:10.1159/000156613 
686 Paul, A., Kuester, J., \& Arnemann, J. (1996). The sociobiology of male-infant interactions 687 688 in Barbary macaques, Macaca sylvanus. Animal Behaviour, 51, 155-170. doi:10.1006/anbe.1996.0013

Paul, A., Preuschoft, S., \& van Schaik, C. P. (2000). The other side of the coin: infanticide and the evolution of affiliative male-infant interactions in Old World primates. In C. P. van Schaik \& C. H. Janson (Eds.), Infanticide by males and its implications, (pp 269-292). Cambridge: Cambridge University Press. doi:10.1017/CBO9780511542312.014

Pfefferle, D., Brauch, K., Heistermann, M., Hodges, J. K., \& Fischer, J. (2008). Female Barbary macaque (Macaca sylvanus) copulation calls do not reveal the fertile phase but influence mating outcome. Proceedings of the Royal Society of London B: Biological Sciences, 275, 571-578. doi:10.1098/rspb.2007.1499

R Core Team, (2014). R: A language and environment for statistical computing. R Foundation for Statistical Computing, Vienna, Austria. 2013. Retrieved from http://www.R-project.org

Rosenbaum, S., Vigilant, L., Kuzawa, C. W., \& Stoinski, T. S. (2018). Caring for infants is associated with increased reproductive success for male mountain gorillas. Scientific Reports, 8, 15223. doi:10.1038/s41598-018-33380-4

Semple, S. (1998). The function of Barbary macaque copulation calls. Proceedings of the Royal Society of London B: Biological Sciences, 265, 287-291. doi:10.1098/rspb.1998.0294

Semple, S., \& McComb, K. (2000). Perception of female reproductive state from vocal cues in a mammal species. Proceedings of the Royal Society of London B: Biological Sciences, 267, 707-712. doi:10.1098/rspb.2000.1060 
710

711

712

713

714

715

716

717

718

719

720

721

722

723

727

728

Seyfarth, R. M. (1978). Social relationships among adult male and female baboons. I. Behaviour during sexual consortship. Behaviour, 64, 204-226. doi:10.1163/156853978X00044

Silk, J. B., Altmann, J., \& Alberts, S. C. (2006). Social relationships among adult female baboons (Papio cynocephalus) I. Variation in the strength of social bonds. Behavioral Ecology and Sociobiology, 61, 183-195. doi:10.1007/s00265-0060250-9

Small, M. F. (1989). Female choice in nonhuman primates. American Journal of Physical Anthropology, 32, 103-127. doi:10.1002/ajpa.1330320506

Small, M. F. (1990). Promiscuity in Barbary macaques (Macaca sylvanus). American Journal of Primatology, 20, 267-282. doi:10.1002/ajp.1350200403

Smuts, B. B. (1985). Sex and friendship in baboons. New York, Aldine de Gruyter. doi:10.1016/0162-3095(86)90007-5

Smuts, B. B, \& Gubernick, D. J., (1992) Male-infant relationships in nonhuman primates: paternal investment or mating effort? In: B. S. Hewlett (Ed.), Fatherchild relations: cultural and biosocial contexts (pp 1-30). New York: Aldine de Gruyter. doi:10.1002/ajhb.1310060321

Städele, V., Roberts, E. R., Barrett, B. J., Strum, S. C., Vigilant, L., \& Silk, J. B. (2019). Male-female relationships in olive baboons (Papio anubis): parenting or mating effort? Journal of Human Evolution, 127, 81-92. doi:10.1016/j.jhevol.2018.09.003

Stumpf, R. M., Martinez-Mota, R., Milich, K. M., Righini, N., \& Shattuck, M. R. (2011). Sexual conflict in primates. Evolutionary Anthropology: Issues, News, and Reviews, 20, 62-75. doi:10.1002/evan.20297 
734

735

736

737

738

739

740

741

742

743

744

745

746

747

748

749

750

751

752

753

754

755

756

757

Taub, D. M. (1980a). Female choice and mating strategies among wild Barbary macaques (Macaca sylvanus L.). In D. G. Lindburg (Ed.), The macaques: studies in ecology, behavior and evolution (pp 287-344). New York: Van Nostrand Reinhold. doi:10.1002/ajpa.1330570117

Taub, D. M. (1980b). Testing the 'agonistic buffering' hypothesis. Behavioral Ecology and Sociobiology, 6, 187-197.

Taub, D. M. (1982). Sexual behavior of wild Barbary macaque males (Macaca sylvanus). American Journal of Primatology, 2, 109-113.

Taub, D. M. (1984). Male caretaking behavior among wild Barbary macaques (Macaca sylvanus). In D. M. Taub (Ed.), Primate paternalism (pp 20-55). New York: Van Nostrand Reinhold. doi:10.1002/ajpa.1330670214

Trivers, R. L. 1972. Parental investment and sexual selection. In B. Campbell (Ed.), Sexual selection and the descent of man (pp 136-179). Chicago, Aldine-Atherton. doi:10.1126/science.179.4075.788

van Noordwijk, M. A. \& van Schaik, C. P. (2000). Reproductive patterns in eutherian mammals: adaptations against infanticide? In C. P. van Schaik \& C. H. Janson (Eds.), Infanticide by males and its implications, (pp 322-360). Cambridge: Cambridge University Press.

van Schaik, C. P., Pradhan, G. R., \& van Noordwijk, M. A. (2004). Mating conflict in primates: infanticide, sexual harassment and female sexuality. In P. M. Kappeler \& C. P. van Schaik (Eds), Sexual selection in primates: new and comparative perspectives (pp 131-150). Cambridge: Cambridge University Press .

Weingrill, T. (2000). Infanticide and the value of male-female relationships in mountain chacma baboons. Behaviour, 137, 337-359. doi:10.1163/156853900502114 
758 Whitten, P. L. (1987). Infants and adult males. In B. B. Smuts, D. L. Cheney, R. M.

759

760

761

762

763

764

765

766

767

768

769

770

771 Seyfarth \& T. T. Struhsaker (Eds.), Primate societies (pp 343-357). Chicago: University of Chicago Press. doi:10.1126/science.240.4855.1076-a

Woodroffe, R., \& Vincent, A. (1994). Mother's little helpers: patterns of male care in mammals. Trends in Ecology \& Evolution, 9, 294-297. doi:10.1016/01695347(94)90033-7

Wright, P. C. (1990). Patterns of paternal care in primates. International Journal of Primatology, 11, 89-102. doi:10.1007/BF02192783

Young, C., Majolo, B., Heistermann, M., Schülke, O., \& Ostner, J. (2013). Male mating behaviour in relation to female sexual swellings, socio-sexual behaviour and hormonal changes in wild Barbary macaques. Hormones and Behavior, 63, 3239. doi:10.1016/j.yhbeh.2012.11.004

Zhao, Q.-K. (1996). Male-infant-male interactions in Tibetan macaques. Primates, 37, 135-143. doi:10.1007/BF02381401 
TABLE 1

\begin{tabular}{|c|c|c|c|c|}
\hline Hypothesis & Predictions & Predictors $^{\dagger}$ & Response & Supported \\
\hline $\begin{array}{l}\text { Paternal investment } \\
\text { hypothesis, female } \\
\text { perspective }\end{array}$ & $\begin{array}{l}\text { 1) The more a female mated with a specific male } \\
\text { (relative to all her matings) the more care her } \\
\text { infant will subsequently receive from this male } \\
\text { (relative to all male care the infant receives) }\end{array}$ & $\begin{array}{l}\text { 1. Distribution of } \\
\text { female matings } \\
\text { 2. Male rank }\end{array}$ & $\begin{array}{l}\text { Distribution of male } \\
\text { care } \mathrm{CSIi}^{\ddagger} \text { in the birth } \\
\text { season following the } \\
\text { mating season }\end{array}$ & No \\
\hline $\begin{array}{l}\text { Paternal investment } \\
\text { hypothesis, male } \\
\text { perspective }\end{array}$ & $\begin{array}{l}\text { 2) The more a male mated with a specific female } \\
\text { (relative to all his matings), the more he will } \\
\text { subsequently care of her infant (relative to all his } \\
\text { infant care) }\end{array}$ & $\begin{array}{l}\text { 1. Distribution of male } \\
\text { matings } \\
\text { 2. Female rank }\end{array}$ & $\begin{array}{l}\text { Distribution of male } \\
\text { care } \mathrm{CSIm}^{\S} \text { in the } \\
\text { birth season following } \\
\text { the mating season }\end{array}$ & Yes \\
\hline
\end{tabular}

\footnotetext{
${ }^{+}$Italics: control predictors
}

^ Composite social index CSIi quantifies how much care the infant received from a particular male relative to all other males ${ }^{\S}$ Composite social index CSIm quantfies how much a particular male cared for a particular infant relative to all other infants 


\begin{tabular}{|c|c|c|c|c|}
\hline $\begin{array}{l}\text { Mating effort } \\
\text { hypothesis, female } \\
\text { perspective }\end{array}$ & $\begin{array}{l}\text { 3) The more care an infant received from a } \\
\text { specific male (relative to all male care the infant } \\
\text { receives), the more often the infant's mother will } \\
\text { mate with him (relative to all her matings) }\end{array}$ & $\begin{array}{l}\text { 1. Distribution of male } \\
\text { infant care in the birth } \\
\text { season prior to the } \\
\text { mating season } \\
\text { 2. Male rank }\end{array}$ & $\begin{array}{l}\text { Distribution of female } \\
\text { matings }\end{array}$ & No \\
\hline $\begin{array}{l}\text { Mating effort } \\
\text { hypothesis, male } \\
\text { perspective }\end{array}$ & $\begin{array}{l}\text { 4) The more a male cared for a specific infant } \\
\text { (relative to all his infant care), the more he will } \\
\text { subsequently mate with the infant's mother } \\
\text { (relative to all his matings) }\end{array}$ & $\begin{array}{l}\text { 1. Distribution of male } \\
\text { infant care } \mathrm{CSIm}^{\S} \text { in } \\
\text { the birth season prior } \\
\text { to the mating season } \\
\text { 2. Female rank }\end{array}$ & $\begin{array}{l}\text { Distribution of male } \\
\text { matings }\end{array}$ & Yes \\
\hline
\end{tabular}




\section{FIGURE LEGENDS}

775 Figure 1. Paternal investment hypothesis based on the female $(F)$ and male (M) 776 perspective. Effect of mating on infant care in the subsequent birth season when adding 777 to the null model (significant from the male perspective).

778 Figure 2. Mating effort hypothesis based on the female $(F)$ and male $(M)$ perspective.

779 Effect of infant care in the preceding birth season on the distribution of matings when 780 adding to the null model (significant from the male perspective). 


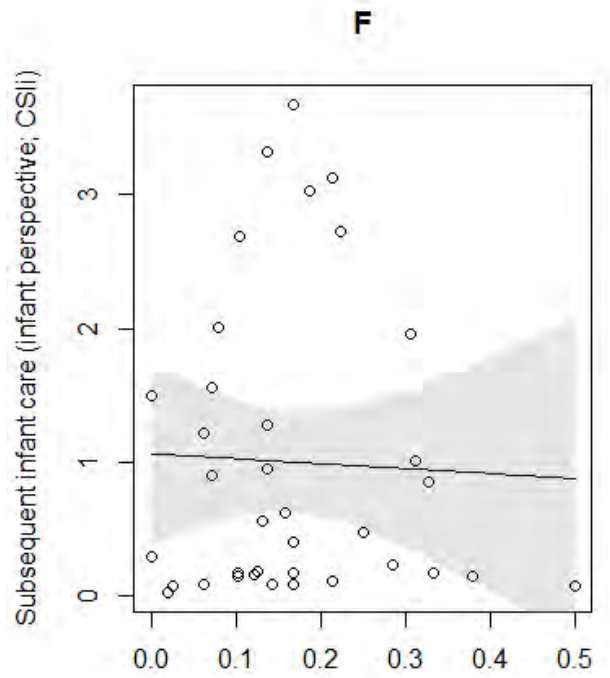

Proportions of matings (female perspective)

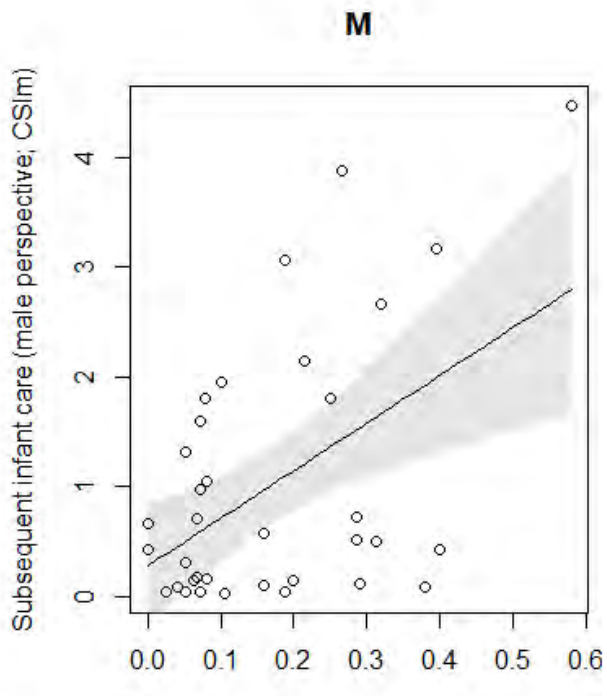

Proportions of matings (male perspective)

Figure 1. Paternal investment hypothesis based on the female ( $F$ ) and male (M) perspective. Effect of mating on infant care in the subsequent birth season when adding to the null model (significant from the male perspective). 


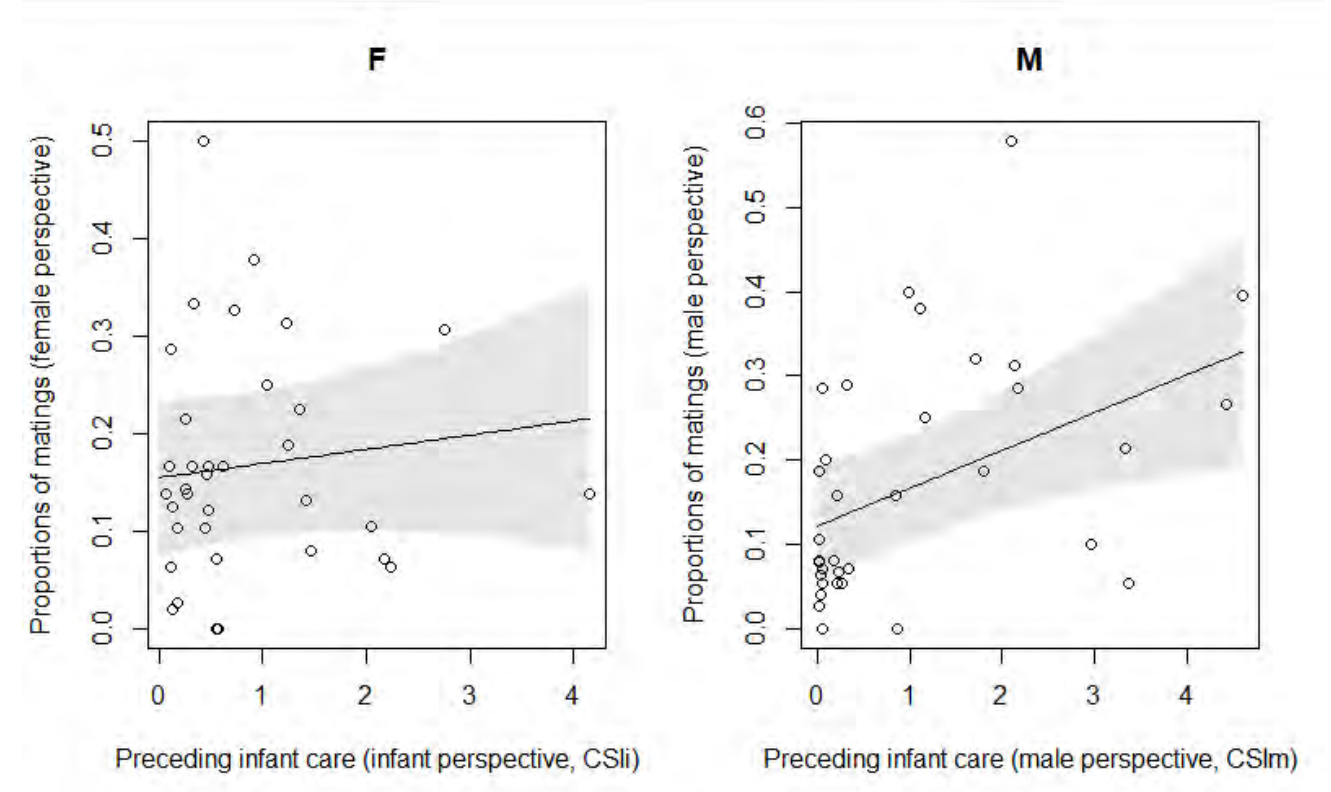

Figure 2. Mating effort hypothesis based on the female (F) and male (M) perspective. Effect of infant care in the preceding birth season on the distribution of matings when adding to the null model (significant from the male perspective).

$211 \times 132 \mathrm{~mm}(96 \times 96 \mathrm{DPI})$ 